\title{
De la donna angelicata a la amante ocasional en la poesía de Benítez Reyes
}

\author{
From the donna angelicata to the occasional lover in the incipient poetry by \\ Benítez Reyes
}

\author{
María Isabel López Martínez \\ milopez@unex.es \\ Universidad de Extremadura, España
}

Recepción: 12 Agosto 2019

Aprobación: 10 Mayo 2020

Publicación: 02 Noviembre 2020

Cita sugerida: López Martínez, M. I. (2020). De la donna angelicata a la amante ocasional en la poesía de Benítez Reyes. Olivar, 20(32), e082. https://doi.org/10.24215/18524478e 082

\begin{abstract}
Resumen: El artículo estudia la transformación de los códigos amorosos y expresivos que realiza Felipe Benítez Reyes en la primera etapa de su poesía. El poeta reinterpreta a Petrarca y a los escritores clásicos europeos, modificando la imagen de la mujer y su representación en el poema. El retrato femenino individual se convierte en un retrato colectivo de mujeres de la década de los 80 del siglo $\mathrm{XX}$.

Palabras clave: Poesía, Transición democrática, Retrato femenino colectivo, Petrarquismo.

Abstract: The purpose of this article is the investigation of the amorous and expressive code accomplished by Felipe Benítez Reyes in the early stage of his poetry. In the text the image of the woman and its representation is modified by the poet because of his reinterpretation of Petrarca and European classical writers. The individual female portrait becomes a collective portrait of women of the 1980 s.
\end{abstract}

Keywords: Poetry, Spanish transition to democracy, Female collective portrait, Petrarchism.

Desde sus comienzos en 1982, fecha en que Luis García Montero obtiene el Premio Adonais por su libro El jardin extranjero (Moreno, 2001), la corriente literaria bautizada como "otra sentimentalidad” y más tarde "poesía de la experiencia" insistió en la pertinencia de una percepción renovada de las relaciones del ser en el mundo y su reflejo en las letras. El primer marbete responde a la confesión del galardonado quien, en un artículo con visos de manifiesto publicado en El País el 8 de enero de 1983, señalaba: "Romper la identificación con la sensibilidad que hemos heredado significa también participar en el intento de construir una sentimentalidad distinta, libre de prejuicios" (García Montero, 1983, pp.9-15). Tal presupuesto es significativo para este estudio, que aborda la reversión de los códigos amorosos y expresivos de la tradición emprendida por Felipe Benítez Reyes, uno de los miembros del grupo, en su etapa poética inicial.

Entre los presupuestos teóricos de la "poesía de la experiencia" priman la vuelta al realismo y a un intimismo no siempre confesional o, a mi parecer, con confesionalidad sui generis; el retorno a la anécdota, que paradójicamente refuerza la consciencia del artificio del poema; la recuperación de las estrofas clásicas que -añado- no desbancan al versolibrismo (Iravedra, 2007); el lenguaje coloquial y la consideración antirromántica del poeta como artífice y de la poesía como oficio (Moreno, 2001, p. 76). 
La reproducción poética de los avatares cotidianos, que ha llevado a tildar incluso a esta corriente de nuevo realismo, ha dado lugar a afirmaciones sobre su mayor preocupación por "la dimensión social y humana de la escritura que por la escritura en sí misma” (Moreno, 2001, p. 76), aserto que apenas se sostiene a la vista del maremágnum de referencias a escritores y a libros ${ }^{1}$. Además, riadas de metapoesía discurren por los versos, causadas por el deseo de trasvasar los planteamientos teóricos a la exercitatio literaria y, de manera inmanente, por el concepto de poeta-artífice que deja muestras prácticas de su oficio, buceando asimismo en los enigmas del lenguaje ${ }^{2}$.

Puesto que la herencia es el caudal donde sumergirse, incluso para nadar contracorriente, proliferan los diálogos con la tradición (Jurado, 2014), sostenidos con distintos parámetros que los novísimos ${ }^{3}$. Los autores desmitifican el quehacer poético y contemplan irónicamente el hipertexto, con una postura "a caballo entre la burla y el rendido homenaje” (Moreno, 2001, p. 78), como corresponde a la postmodernidad del fin de siglo. La intertextualidad es el "punto de referencia imprescindible, es el terreno de la complicidad entre el poeta y el lector” (Moreno, 2001, 80). Sobresalen clásicos europeos como Petrarca y escritores áureos españoles, mientras que de períodos más recientes atraen los simbolistas, los modernistas y la Generación del 50, con Gil de Biedma a la cabeza (Molina Campos, 1988, p. 42). Se ha afirmado a propósito de un miembro del grupo, pero extensible a otros, que un rasgo de la escritura de la experiencia "rediviva" es "la nebulosa relación entre la creación (originalidad) poética, la refundición de la tradición y la traducción” (Mudrovic, 2000, p. 32).

Con antecedentes en el amor cortés, el petrarquismo cantó a la mujer inaccesible, que provoca en el amante un dolorido sentir perenne y exclusivo ("polvo serán mas polvo enamorado", declaraba Quevedo). Consagró un ideal y una convención literaria que atravesaron centurias, pese al tropel de réplicas y contrafacta. En la novela y en el teatro pululan personajes con relaciones múltiples, normalmente negativos, antagonistas y origen de conflictos, como la figura de don Juan, prototipo que supera las barreras de género literario, lengua y época. En lírica decrece la cantidad de composiciones de tono grave que incorporan este asunto y sorprenden las muestras en la "poesía de la experiencia", en particular durante su eclosión, cercana a la Transición democrática española. En este período, que comienza con la muerte del general Franco en 1975 y se extiende en la década de los 80 , se asiste a cambios sociopolíticos de tal profundidad que calan en los hábitos vitales, impregnando incluso las relaciones afectivas (Sanz, 2016). Son los años de la Movida, movimiento contracultural paralelo a la despenalización de la homosexualidad, la venta libre de anticonceptivos, la pujanza del feminismo y la propensión a una sociedad laica.

Los poetas de "la otra sentimentalidad" son adolescentes o muy jóvenes entonces, pues nacen a finales de la década de los 50 y en los sesenta -los protagonistas activos de la Movida son un poco mayores-, pero perciben la coyuntura sociopolítica y viven los cambios, aunque el núcleo de su producción literaria surgirá después. El citado afán de construir una sentimentalidad diferente y "libre de prejuicios" se plasma en motivos literarios, entre los que despunta la sustitución de la amada única y objeto de una devoción eterna por un ser de quien no se refleja ni siquiera el nombre. En esta órbita es ilustrativa la fase inicial de la producción poética de Felipe Benítez Reyes reunida en el volumen Poesía (1979-1987). El poema más sugestivo al respecto se titula "La desconocida" y pertenece a Los vanos mundos, un libro compuesto entre 1982 y 1984:

En aquel tren, camino de Lisboa,

en el asiento contiguo, sin hablarte

- luego me arrepentí.

En Málaga, en un antro con luces

del color del crepúsculo, y los dos muy fumados,

y tú no me miraste.

De nuevo en aquel bar de Malasaña,

vestida de blanco, diosa de no sé

qué vicio o qué virtud.

En Sevilla, fascinado por tus ojos celestes 


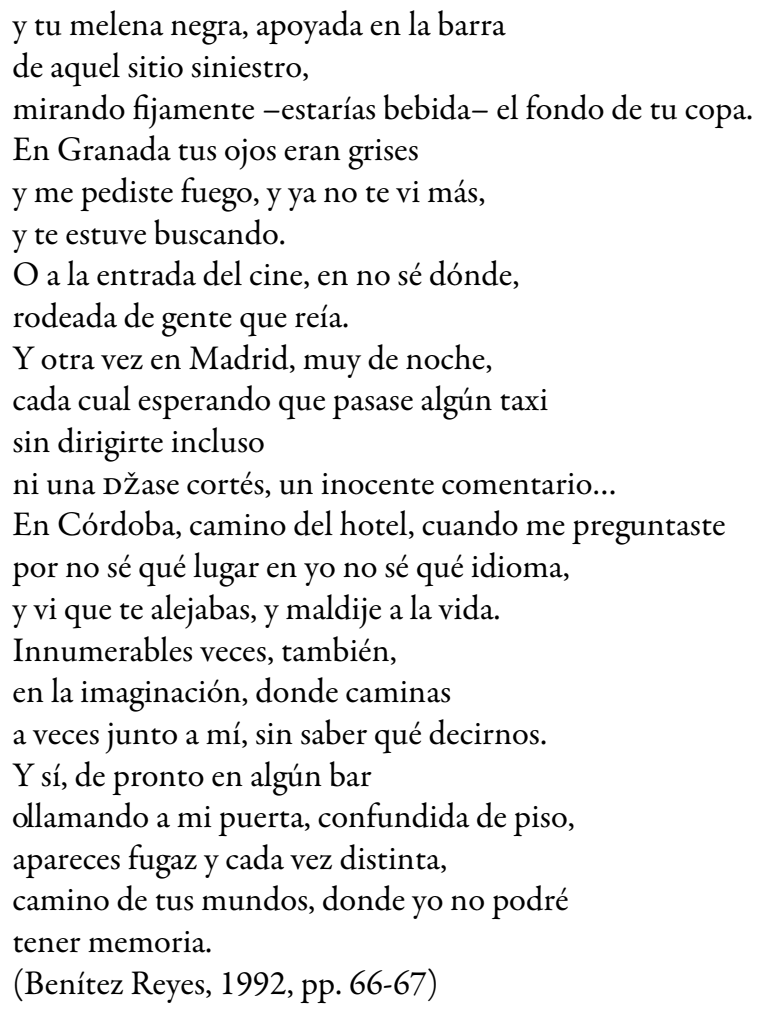

El motivo medular, la exaltación de la mujer inaprehensible y efímera, es una pieza del desmontaje de lo elevado que acomete la poesía de la experiencia. En un nivel general este proceso se constata al trocar la confesión por la ficción y la persona por el personaje (García Montero en Benítez Reyes, 1992, p. 15), aunque los resquicios de los primeros polos (confesión y reflejo de la persona) asoman y provocan el traslado a la página de la vivencia cotidiana -incluida la biblioteca de autor-, aportando el cariz de época. Para romper la disonancia entre lo vivido y las convenciones escritas, las circunstancias genuinas del último tercio del siglo XX emergen en los versos, introduciendo trazas de un costumbrismo diferenciador. La dicotomía ficción-realidad presenta perfiles complejos en esta estética, porque, como señaló Sánchez Torre (1977, p. 12) respecto a las primeras etapas de la poesía de Felipe Benítez Reyes, se trata de una poesía "sumamente literaturizada" donde "la ostentación del artificio, la metapoesía cobra [...] el cariz de mecanismo de defensa, ante sí mismo y ante el lector, contra la identificación romántica del yo poético con el yo real” . Sin embargo, no se restaña la efusión de un tipo concreto de sensibilidad ni se ciega la visión de mundo de un autor enmarcado en su tiempo y en sus orteguianas circunstancias.

El asunto de "La desconocida" se agavilla en el haz de motivos gratos a Benítez Reyes, sobre todo en su fase inicial, $v$. $g r$., el "mundo fugitivo de la evocación, de la pérdida" y de la inconsistencia que comporta el paso del tiempo (Pérez García, 2007; Maqueda Cuenca, 2006), que en este caso se proyecta en la imposibilidad de comunicación amorosa, sea por voluntad o por destino. Señala García Montero: "La poesía acepta lo transitorio sin necesitar la quietud consoladora de alguna sublimación" (García Montero en Benítez Reyes, 1992, p. 20). No obstante, la transitoriedad también guarda ciertas claves del misterio de la existencia y, por ello, atrae y merece ser consignada mediante la palabra literaria 5 .

En "La desconocida" Benítez Reyes entabla un juego dialéctico con la tradición, invirtiendo los códigos al desplazar los elementos heredados hacia contextos significativos asombrosos. Así, en la dispositio la estructura es semejante a la de los sonetos de definición del amor afamados en los Siglos de Oro, del tipo de las divulgadísimas y excelentes proposiciones de Lope de Vega en "Desmayarse, atreverse, estar furioso", que culminan en el endecasílabo "Esto es amor, quien lo probó lo sabe"; de Quevedo en "Es hielo abrasador, es 
fuego helado"; del conde de Villamediana en el hermoso "Determinarse y luego arrepentirse". Góngora, por su parte, legó joyas sobre los celos en “ $\mathrm{O}$ h niebla del estado más sereno”.

En los citados sonetos renacentistas y barrocos y en "La desconocida", la estructura se asienta en una extensa enumeración descriptiva. En los primeros, los tercetos o incluso el verso final atesoraban la clave o el epifonema, para someter al lector a una tensión similar a la de las adivinanzas y fomentar su expectación, toda vez que solían estar despojados del título orientativo (tal epígrafe se debía a los editores con vistas a la organización de los textos). Benítez Reyes adelanta la palabra objeto de definición y la sitúa en el título, con una estrategia aplicada en otros poemas de Los vanos mundos como "La juventud" y "Los espejos" (Piquero, 1996). Mientras en estas composiciones la yuxtaposición de metáforas facilita la definición, en "La desconocida" sucesivos espacios y tiempos acogen los sucintos rasgos de retratos femeninos. En ambos casos la enumeración resulta esencial, aunque no sea tan caótica como se ha señalado respecto a este poema y a "F.S.F." (Piquero, 1996).

No funciona una estructura hipertensiva con desembocadura en un epifonema al uso áureo, pero persisten la enumeración y las dos partes cuantitativamente descompensadas con resolución en la última, punto de desembocadura tras el fluir de situaciones ensartadas. Coadyuva al encadenamiento el polisíndeton en la copulativa que se proyecta incluso repetido en un mismo metro (v. 15 "y me pediste fuego, y ya no te vi más"). Los versos 1 al 25 repasan los entornos y circunstancias de los fugaces cruces "sentimentales" en el pasado, mientras que del verso 26 al 33 surge el presente, pero ya abriendo el espacio inconcreto de la imaginación o las hipótesis de futuro. Del ayer solo resta un rastro nebuloso en el recuerdo, pero las situaciones pueden repetirse igual de inconsistentes y volátiles, según las tendencias amorosas de los nuevos tiempos.

Una combinación dual de versos largos, que oscilan entre las 10 y las 19 sílabas, y breves con primacía del heptasílabo, alienta un perceptible ritmo de silva libre, que precisa una columna vertebral rítmica, cuyo fuste es la enumeración regida por una anáfora, a veces con deícticos que señalan la distancia espacial y temporal de las escenas evocadas. Aquí tal figura retórica se apoya en los complementos circunstanciales de lugar, que al principio recorren espacios físicos ("En aquel tren, camino de Lisboa...", "En Málaga...", "De nuevo en aquel bar...”, “En Sevilla...”, “En Granada...”, “O a la entrada del cine...”, "Y otra vez en Madrid...”, “En Córdoba...”) y al final, ámbitos imaginarios o hipotéticos.

En el primer plato de la balanza que recoge las circunstancias concretas de época y autor (el segundo plato sostiene la "literaturización" que quiebra lo puramente confesional), surgen ciudades frecuentadas por el poeta, nacido en Rota en 1960 y estudiante en la década de los 80 en la Universidad de Cádiz y en la de Sevilla. Las vivencias anotadas eran comunes a los jóvenes coetáneos que se movían por enclaves universitarios favorables a la marcha y, aunque resulte paradójico, aportan notas de generalización y difuminan lo estrictamente biográfico. Destacan, además de Madrid como imán, ciudades andaluzas que suman el ingrediente cosmopolita del turismo, y la oceánica y fascinante capital del país vecino, muy visitada por su cercanía a España y sus atractivas diferencias. En un movimiento de travelling de aproximación, se suceden los medios de transporte (el tren, el taxi) como insignias de un sujeto en absoluto estático, desligado de una tierra específica, que se define por una movilidad con la inconsistencia de la modernidad líquida, en palabras de Bauman.

El viaje no forzado por la emigración laboral y emprendido por los universitarios complementa en la España de los 80 al despertar de la democracia y de la bonanza económica. El 12 de junio de 1985 se firmó el Acta de Adhesión de España a las Comunidades Europeas, tratado por el que el país ingresó el 1 de enero de 1986 en la actual Unión Europea. Esta adhesión rompió el aislamiento internacional y contribuyó decisivamente a liberalizar y racionalizar la economía española, además de abrir las fronteras. En el estrato juvenil, la apertura sustancial fue favorecida a partir de 1987 por la creación del programa Erasmus (European Region Action Scheme for de Mobility of University Students). No parece fortuito que en el poema intervenga una chica extranjera: "En Córdoba, camino del hotel, cuando me preguntaste / por no sé qué lugar en yo no sé qué idioma”. 
Entre los emplazamientos, se repiten los de la capital de España ("Y otra vez en Madrid"), en un movimiento pendular opuesto al itinerario lineal que simboliza la vida con destino único y prefijado. Se reitera una locución preposicional con semas de desplazamiento, que al principio indica destinos físicos ("camino de Lisboa", "camino del hotel") y al final, abstractos y metafóricos ("camino de tus mundos"). En suma, un sujeto poco aferrado a recintos estables transita por diversas zonas y circunstancias atraído por el misterio del conocimiento del otro, de la pareja anhelada que no integrará una relación trascendente y única, sino que se encarna en múltiples mujeres con quienes no se establece una comunicación fluida. El sujeto no presenta síntomas de insatisfacción o melancolía, aunque se adivina la sensación de pérdida de oportunidades por timidez o por azar. El concepto de relaciones amorosas es característico de la salida de la adolescencia y de la juventud, cuando se confía en el carpe diem en su versión de aprovechar al máximo las variadas experiencias sensuales y eróticas. Así se aprecia en el poema "Murmullos en la escuela neoplatónica" (Benítez Reyes, 1992, p. 34) del primerizo Paraíso manuscrito (1979-1981) donde, en un monólogo dramático, un filósofo aconseja a los discípulos la seducción y la escritura para atraer "sabiduría a la academia de las almas" y rechazar el riesgo de ser "estables amadores / de un solo cuerpo hermoso" porque con ello se pierde "cuanto el amor requiere -y el poema requiere- / de intriga y de secreto"6.

Las escenas de "La desconocida" son urbanas, acordes con la "poesía de la experiencia" (Iravedra, 2007), porque los acontecimientos emblemáticos de la década de los 80 en España acaecen en las ciudades. Se esbozan los sitios de concurrencia juvenil: el bar, el cine, la calle, el hotel, el piso de estudiantes..., que Benítez Reyes también reproduce con altas dosis de humor en la novela El novio del mundo. A diferencia de los topónimos de las localidades, en el poema se opta por la indeterminación ("en un antro", "en aquel bar", "en la barra de aquel sitio siniestro", "a la entrada del cine”), porque se trata de instantáneas recordadas sin nitidez plena.

En sintonía, se omite el antropónimo de las chicas evocadas. En el petrarquismo, en estéticas por él aureoladas en los Siglos de Oro o posteriormente -léanse los Cien sonetos de amor que Neruda dedica a Matilde- y en amplias áreas de la tradición, el nombre de la amada ilustra sobre atributos de su identidad. De hecho, el apelativo Laura se presta a multitud de juegos de palabras, provocando asociaciones mitológicas con Dafne y metáforas sacroprofanas que subliman a la mujer (Laura-aura). En "La desconocida" ni siquiera se tiene acceso al nombre femenino, dada la fugacidad de los encuentros. No es preciso conocerlo o imprimirlo, porque falta el afán de diferenciar a la mujer y distinguirla como única. Sin embargo, en línea con el petrarquismo, sí confiere relevancia al enclave y al tiempo como sucedía en el famosísimo soneto LXI "Benedetto sia 'l giorno, e 'l mese e l'anno", del Canzoniere de Petrarca, también organizado sobre anáforas y enumeraciones .

Benítez Reyes comparte con Petrarca la fascinación por los ojos de la mujer, pero no porque sean vehículo del espíritu o de los efluvios amorosos como preconizaba el neoplatonismo y cantaba Garcilaso en el soneto VIII ("De aquella vista pura y excelente / salen espirtus vivos y encendidos, / y siendo por mis ojos recebidos, / me pasan hasta donde el mal se siente"), sino por su atractivo ("En Granada tus ojos eran grises"), a veces sorprendente por el contraste con el pelo ("fascinado por tus ojos celestes / y tu melena negra"). Se rehúsa la habitual comunicación a través de la mirada (“y tú no me miraste”). Omitir los antropónimos supone la renuncia a la mayor ofrenda de un poeta a la amada, la eternidad a través de la palabra, según aduce Petrarca en el terceto final, siguiendo la estela de Propercio, Horacio y Ovidio. Para Benítez Reyes, ella es "la desconocida" en varias dimensiones del término: para el presunto amante por el contacto superficial; para el poeta, remiso a plasmar los acontecimientos ("apareces fugaz y cada vez distinta, / camino de tus mundos, donde yo no podré / tener memoria”) y, en consecuencia, para los lectores a quienes se les veta el acceso a tales recuerdos. Por tanto, el vino nuevo de las experiencias con la amante múltiple en entornos de los años posteriores a la dictadura colma los viejos odres de los códigos tradicionales. El final del poema contemporáneo sigue el trazado del soneto LXI de Petrarca, pero tergiversa los espacios y el elogio a la mujer en exclusiva. La repercusión metaliteraria se manifiesta en el cambio del objetivo de la poesía, que ya no perpetúa la memoria. 
Una de las claves hermenéuticas de "La desconocida" se aloja en el singular del título. Se deconstruye el enfrentamiento tú/yo propio de la poesía amorosa, pues la segunda persona se colma de referencias múltiples, porque varias mujeres conforman ese singular no genérico. No se anhela una mujer completa formada, como Frankenstein, por pedazos de otras, sino una sucesión de seres de quienes se resaltan rasgos físicos (ojos, pelo) y hábitos poco convencionales (ir a antros, estar drogada o bebida). Como la relación es epidérmica, prima la prosopografía de las muchachas en detrimento de la etopeya.

La cercanía física entre el "amante" y las mujeres se debe a que frecuentan los mismos recintos cerrados ("el asiento contiguo" de un tren, el "antro" o bar) o exteriores (en la entrada del cine, en la calle esperando un taxi, camino del hotel, en la puerta del piso), pero siempre son lugares de paso, porque las relaciones son esporádicas y con carencia total de comunicación verbal ("sin hablarte", "sin dirigirte incluso una frase cortés, un inocente comentario...”) o parcial, pues se emiten mensajes casi vacíos de significado (“y me pediste fuego, y ya no te vi más") o ininteligibles ("cuando me preguntaste por no sé qué lugar / en yo no sé qué idioma"). El diálogo falta incluso en la facultad del alma donde se superan todos los impedimentos: "En la imaginación, donde caminas / a veces junto a mí, sin saber qué decirnos". La amada inaccesible de la tradición, elevada a un estrato superior, cede el paso a las chicas que comparten espacios con un pretendiente sin arrojo para seducir ("luego me arrepentí", "y me pediste fuego, y ya no te vi más, / y te estuve buscando", "y vi que te alejabas, y maldije la vida”). Se revela la fatuidad de la palabra para conectar a los seres en una sociedad en la que imperan la caducidad y el cambio.

Los entornos esbozados son análogos a los ambientes canallas de los primeros libros de Benítez Reyes, que envuelven a una juventud tocada por el tempus fugit con el peculiar deje melancólico de timbre irónico. Para favorecer los tonos de cierta falsedad y pose literaria, a veces se pinta un ambiente degradado y un tanto teatral, como corresponde a la disolución de la identidad poeta-sujeto lírico y a la afirmación antirromántica del personaje que proclama la "poesía de la experiencia". El antro con luces crepusculares sugiere la irrealidad ajena a la plenitud diurna.

El submundo de las drogas se esboza con la variante coloquial "estar fumados", un cronolecto relativo al tipo de sustancias consumidas, los cigarrillos con marihuana o hachís, denominados "porros" en jerga. En los 80 los chicos y las chicas comparten garitos y actividades, algo inaudito para la gran mayoría de la generación de sus padres, que nacieron durante la guerra civil o unos años antes y fueron jóvenes en la dictadura. No por casualidad el título del libro en el que se inserta "La desconocida" es Los vanos mundos y el del poemario anterior es Paraiso manuscrito, con una alusión implícita a Les paradis artificiels de Baudelaire.

La vanidad no se mueve en la onda de los antiguos libros de meditación religiosa, como el Tratado de la vanidad del mundo (1775) del franciscano Fray Diego de Estrella, que advertía al fiel del nulo valor de lo material en la salvación humana. Se relaciona con la adolescencia y la juventud perdidas y con la inmersión en esos paraísos artificiales de la noche (Moreno, 1977) que acaban también desvaneciéndose, aunque desde la perspectiva del "hedonismo canalla" como rasgo del "modelo de dicción de muchos de los coetáneos de Benítez Reyes” (Prieto de Paula, 2003), constituyen una porción irrenunciable de la existencia y por ello se plasman ${ }^{8}$.

En Madrid, epicentro de los movimientos contraculturales, se repiten los encuentros del sujeto y las jóvenes explícitamente en el barrio de Malasaña, cuna de la Movida donde se localizaban los bares de mayor afluencia de público y representatividad: El Penta, La Vía Láctea, El Tupper... Benítez Reyes mueve las plantillas tradicionales respecto a las vestiduras blancas de la mujer-diosa que, por mor del encabalgamiento "diosa de no sé / qué vicio o qué virtud" y de la estructura dual y clásica del heptasílabo que acoge una antítesis, no subliman a la dama desdeñosa sino que la convierten en ser supremo del "vicio". Por la dubitatio, este equivale a "virtud", pues ambos términos confluyen como sinónimos. A esta lectura traspasada de ironía contribuye el desplazamiento del balbuceo propio del mutismo ante la intensidad del sentimiento, al estilo de San Juan de la Cruz, hacia terrenos más prosaicos. La duda del sujeto, que actúa como voyeur sin conversar, se debe asimismo a que no conoce en profundidad a la chica. 
Crece la ironía y la desacralización cuando la escena se desarrolla en un "sitio siniestro" de Sevilla y ella, en vez de dirigirle las consabidas miradas de correspondencia, aparece "mirando fijamente -estarías bebida- el fondo de tu copa”, porque la fijeza ocular no responde a interés o reflexión, sino a la embriaguez. El alcohol, que también consume la mujer y ebria es ensalzada, se suma a las drogas y al tabaco cuando la acción se trasladaba a las ciudades andaluzas de Málaga y Granada. A medida que avanza la lectura, se perfilan los cubículos de encuentro (antro, bar, barra, sitio siniestro) y los hábitos.

La incomunicación no proviene de la ausencia o de las prohibiciones a lo Romeo y Julieta que precipitan la tragedia; es fruto de un aislamiento del sujeto entre la multitud: "O a la entrada del cine, en no sé dónde, / rodeada de gente que reía”. Puesto que la memoria todo lo diluye, se omite el nombre y enclave de los bares y el de este cine. El "narrador" cuasi cinematográfico focaliza desde fuera la escena a la manera behaviorista, sin inmiscuirse e ignorando cuestiones trascendentes. En las salas de proyección de la década confluían los jóvenes bajo el reclamo de películas convencionales y de obras de directores que despuntaban como Fernando Colomo, Fernando Trueba y sobre todo Pedro Almodóvar, que en los 80 había estrenado Pepi, Luci, Bom y otras chicas del montón (1980), Laberinto de pasiones (1982), Entre tinieblas (1983), ¿Qué he hecho yo para merecer esto? (1984), Matador (1986), La ley del deseo (1987) y Mujeres al borde de un ataque de nervios (1988), film que fue nominado al Óscar en la categoría de Mejor película extranjera.

A partir del verso 19 y hasta el 26, se evocan encuentros en el exterior, producidos en la omnipresente Madrid y en una nueva ciudad andaluza, Córdoba. Acontecen en la calle durante la noche, que no es "fabricadora de embelecos, loca, imaginativa, quimerista" como en Lope de Vega, sino encuadre para la soledad tras una prolongada velada, que el sujeto constata sin dolor de ausencia y con un eros frustrado. La ironía y el léxico canalla diluyen cualquier conato de imagen sensiblera: "y vi que te alejabas, / y maldije la vida”.

En los siguientes versos la imaginación se eleva a territorio inmaterial para una unión idílica, siempre en tránsito y tocada por el hermetismo que es responsabilidad de la pareja, según marca el plural de la insistente estructura que denota la incomunicación: "donde caminas / a veces junto a mí, sin saber qué decirnos". La coda del poema arranca con la copulativa del polisíndeton que sugiere la continuidad de los encuentros y es la llave de una enumeración que retoma los ambientes físicos que favorecen el cruce de vidas y los proyecta hacia el futuro, sin programaciones y de ahí la indeterminación de los lugares ("en algún bar") y de las circunstancias ("llamando a mi puerta, confundida de piso"). En estas hipotéticas instantáneas la mujer "fugaz y cada vez distinta" representa individualidades sucesivas que, por la inconsistencia del trato, resultan ininteligibles. Puede producirse una intersección ocasional de las sendas de los presuntos amantes, pero las mujeres poseen un mundo personal e inaccesible. El itinerario geográfico de la primera parte del poema se torna metafórico: el destino de cada mujer es un misterio y de ahí la imposibilidad de recordarlo y transmitirlo en la escritura. El poeta tampoco podrá brindarlo como obsequio para la posteridad, según hicieron Propercio, Horacio, Ovidio, Petrarca e incluso Lope de Vega, que ofrecía palabras a cambio de favores amorosos y, al ser descubierto su ardid, plasmaba el juego en el texto como suprema, victoriosa e irónica manera de insistencia?

Aunque sea el más representativo, "La desconocida" no es el único poema de la primera época de Benítez Reyes que aborda una nueva concepción de la mujer a partir de un contrafactum de los códigos tradicionales, atrayéndolos a la realidad inmediata y desmitificando con la ironía. "Las niñas" de La mala compañia (1985-1987) contiene otro retrato de las jóvenes:

Llegan con los tacones sucios del barro de los parques, con un perfume espeso de flores venenosas.

Llegan con gafas negras, radiantes, despeinadas;

la noche las recubre con un palio morado.

Toman licores densos con aire de tragedia.

Tienen nombres de diosa, de colonia o de gato. 
No son invulnerables a las historias tristes y huyen de madrugada, como lunas esquivas.

(Benítez Reyes, 1992, p. 124)

La enumeración de metáforas define a las jóvenes de los años 80 , denominadas coloquial y afectivamente "niñas" con un vocablo que será desbancado por el jergal y más crudo "tía”. El retrato es colectivo porque se pintan las costumbres de pandillas de la época, que no alcanzan la categoría de las bandas urbanas de moda entonces, como los punk, mod, etc., donde la individualidad se diluye.

El verso libre de base tradicional ahora se cierne sobre la octava que hilvana alejandrinos blancos, excepto el primer verso de dieciséis sílabas10. La anáfora torna a ser columna rítmica, asentada sobre el verbo "Llegan" que, en un travelling de aproximación, insiste en presentar a las jóvenes en movimiento, no asidas a lugar ni a afectos constantes, a diferencia del confinamiento doméstico contra el que se rebelan. El parque dista provocar el spleen romántico o modernista que fluye en soledad y pasa a convertirse en sitio de cita juvenil sobre todo cuando irrumpe el "botellón".

El retrato grupal de las niñas reproduce con ironía el atuendo de la época, por ejemplo los tacones, calzado poco adecuado para el "barro". La ósmosis entre espacio y persona permite que las chicas exhalen "un perfume espeso de flores venenosas", en sintonía con los gustos olfativos de entonces, renuentes a las fragancias frescas. La nota diferenciadora se halla en el verso "Llegan con gafas negras, radiantes, despeinadas", que remite a la moda punk, que admitía tales lentes durante la noche, además los cardados y crestas, y de ahí el calificativo ensalzador "radiantes". En la tensión entre el costumbrismo y la distancia irónica interviene la literaturización, que justifica la imagen cultista y desacralizadora "la noche las recubre con un palio morado". La mujer diosa es sustituida por las chicas que deambulan hasta el amanecer, cuyos colores justifican la analogía de la noche y el dosel que resguarda al Santísimo Sacramento en las procesiones.

Las chicas ingieren "licores densos" en vez de las bebidas antes convencionales, con "aire de tragedia" por sus posturas de rebeldía y su indumentaria negra. Asoma el tópico del theatrum mundi, que aporta a la instantánea alguna dosis de falsedad. Al eludir los antropónimos femeninos, el humor aflora en la reificación de los dos miembros finales de la enumeración, que chocan con la inicial e insistente imagen sacroprofana: "Tienen nombre de diosa, de colonia o de gato". Se mantiene el equilibrio entre el retrato costumbrista y la ironía, porque con el desarrollismo, la influencia de la televisión, el incremento del turismo, los viajes y la relajación de los preceptos católicos que obligaban a recurrir al santoral, habían proliferado antropónimos inusuales, la mayoría de origen mitológico o extranjero. Si las bautizadas en los años cincuenta y sesenta se solían llamar María seguido de una advocación de la Virgen (Carmen, Pilar...) o de santas (Teresa, Isabel...), en las décadas siguientes responden a Diana, Silvia, Rocío, Anaís, Noa, Ágata y diminutivos propios de animales. Los dos versos finales sacan a relucir la interioridad de esas niñas que, pese a su aspecto rompedor, son sensibles a ciertas estrategias de seducción, a las "historias tristes" tal vez contadas por los pretendientes. La tópica equivalencia de la luna y la mujer para realzar que esta es única, hermosa y de nivel superior sufre una vuelta de tuerca, por la suma de un elemento de analogía relativo a la movilidad: todas "huyen de madrugada".

El apelativo "niñas" aplicado a las jóvenes resurge en la sección IV de "Serie menor" titulada "Galatea", que pertenece al ciclo de Los vanos mundos (1982-1984). Las convenciones literarias se desmontan al aplicar el idealizado sobrenombre pastoril a un maniquí situado tras una "luna enigmática" que dista de ser el satélite de la tierra. Leemos:

\footnotetext{
Vagamente espectral, con la mirada fija y en el aire las manos quietas, como dormida

por un encantamiento, con esa soledad
} 


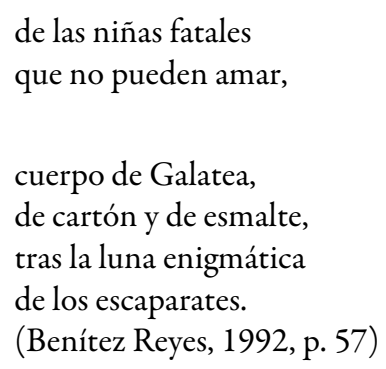

A despecho del carácter antivanguardista de la "poesía de la experiencia”, estos versos siguen la poetización de máquinas y objetos que ya emprendió el futurismo ${ }^{11}$. La personificación de la muñeca se alinea con la postura antirromántica que, en sentido inverso, implica una cosificación de la mujer. El maniquí suple al ser vivo y, a la inversa, este se comporta como un objeto. No obstante, la consumista chica-maniquí sin afectividad y estática difiere del modelo de mujer expuesto por Benítez Reyes en sus primeros libros.

La irreverencia hacia la tradición cultural a partir de nombres de mujeres míticas brota asimismo en el poema "Helena" (Benítez Reyes, 1992, p. 65) de Los vanos mundos, que trata sobre una prostituta extranjera que ejerce en España: "Helena de un país hecho de nieve, / zorra plateada en las noches costeras". El antropónimo de la bella por antonomasia que provocó la guerra de Troya se aplica a una realidad actual y sórdida, tocando una clave de la poesía de la experiencia: volcar las referencias culturales en un entorno cotidiano que incluye los ambientes canallas, produciendo una mezcla que yuxtapone lo elevado y las experiencias convencionales ${ }^{12}$. Recurrir a mundo grecolatino para descontextualizarlo y contemplarlo desde la distancia irónica supone agudizar la capacidad analítica que ha de cernirse sobre la realidad, tal y como preconizaba Luis García Montero en el manifiesto germinal del grupo: "Cuando la poesía olvida el fantasma de los sentimientos propios se convierte en un instrumento objetivo para analizarlos (quiero decir, para empezar a conocerlos). Entonces es posible romper con los afectos, volver sobre los lugares sagrados como si fueran simples escenarios, utilizar sus símbolos como si fueran metáforas de nuestra historia" (García Montero, 1983, p. 15).

Frente a la anonimia de las mujeres en "La desconocida", en el "Poema de los seres imaginarios" de Los vanos mundos sucesivos antropónimos femeninos encabezan la enumeración, seguidos de las respectivas aposiciones paralelísticas que bosquejan los respectivos retratos femeninos:

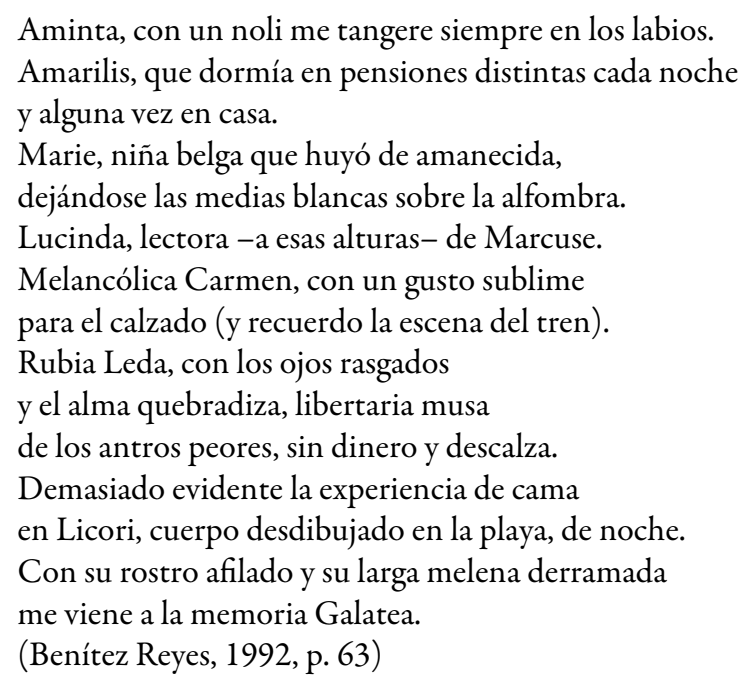

Los pseudónimos procedentes de la literatura clásica se alternan con los antropónimos corrientes, alguno de los cuales -Carmen- irradia connotaciones relativas a la española fatal de Merimée pero que, con la técnica general de contrastes que rompen las expectativas, lleva antepuesto el adjetivo "melancólica”. Leda, 
cantada con aquilatado erotismo por el admirado Rubén Darío en "Blasón" y en "El cisne en la sombra parece de nieve", se desnuda de sus galas mitológicas y toma una mundana condición de pobre y descalza "musa libertaria", opuesta a cualquier origen divino, porque "ni Dios, ni patria, ni rey" proclamaba el lema anarquista.

Cada mujer proporciona una experiencia sensual o sexual, a veces sugeridas por el apelativo que se subvierte. Así acaece al transcribir en latín la expresión de recato noli me tangere que, repetida por la chica, le resta una credibilidad que se tambalea con la desacralización de la frase que, según el evangelio de San Juan (c. 20, v. 17), Cristo resucitado dirigió a María Magdalena, la prostituta redimida ${ }^{13}$. Los personajes tampoco son estáticos y se producen encuentros en el tren, la playa, las pensiones y, otra vez, en "los antros peores", que suma a la evocación de las experiencias eróticas con frecuencia nocturnas el consabido ambiente canalla.

La mujer sigue siendo fugaz y, así, Marie, extranjera como el personaje de "La desconocida", "huyó de amanecida" al igual que las niñas-luna. Su indumentaria blanca tampoco implica pureza, pues se trata de las medias abandonadas que delinean un deshabillé in absentia. El ambiente universitario justifica a la lectora de Marcuse, atacada por el dardo humorístico cuando se la tacha de pasada de moda. El filósofo alemán Herbert Marcuse, miembro de la primera generación de la Escuela de Frankfurt, fue especialmente crítico con la sociedad capitalista, según expuso en sus libros Eros y la civilización (1955) y El hombre unidimensional (1964), que tuvieron gran ascendencia en el movimiento estudiantil de los sesenta, junto a la propensión del autor a expresar sus ideas acerca de las protestas juveniles. De todo ello, como decía el admirado Gil de Biedma, ya habían pasado veinte años, período que justifica que se tilde de desfasada a la lectora de Marcuse. Los habituales y decentes elogios a los miembros atractivos y visibles de las mujeres ("ojos rasgados", "larga melena derramada", rostro) se alternan con los detalles eróticos que se sugieren ("gusto sublime para el calzado", "cuerpo desdibujado en la playa") o se exponen en general ("Demasiado evidente la experiencia de cama").

En todo caso, en el núcleo del poema se halla la desacralización de los nombres o pseudónimos de la mujer sublimada en la tradición, que se logra al aplicarlos a una realidad nada idealizada y expuesta con sermo humilis. Las lecturas convencionales son redireccionadas y las palabras gastadas cobran nueva vida. En los poemas revisados el proceso pasa por un emergente concepto de retrato femenino que abandona la representación del personaje único en favor de un retrato colectivo que pinta los tipos de mujer percibidos por los jóvenes de finales de la década de los 70 y los años 80 del siglo XX, período de vertiginosos cambios sociales especialmente en España, que dejan su impronta en el giro en los usos amorosos.

Tal como sucedía en la pintura clásica, por ejemplo en El nacimiento de Venus de Botticelli, cuando en literatura se realizan retratos literarios de grupo con figuras femeninas, el foco suele enfatizar a la protagonista. En los poemas de Benítez Reyes se borra el protagonismo individual, como compone Picasso en Les demoiselles d'Avignon. El ideal cerrado, compacto, perfecto, fijo y homogéneo de mujer es sustituido por la heterogeneidad y el ir haciéndose no solo del yo-emisor, también de la imagen del tú, que posee asimismo una identidad incompleta y en proceso. Las chicas que desfilan por los versos de "la otra sentimentalidad" adoptan actitudes muy diferentes a sus predecesoras, pues leen filosofía, mantienen relaciones sexuales ocasionales, viajan, beben, se drogan, van a garitos, viven la noche... La percepción corresponde a un hombre, sujeto que focaliza y no da voz directa a los personajes femeninos, algo que sí ocurre en poemas bastante subversivos de escritoras -léase, por ejemplo, "Chico wrangler" de Indicios vehementes (1985) de Ana Rossetti-, pero ese es asunto para otro momento o, en román paladino, harina de otro costal.

\section{REFERENCIAS}

Benítez Reyes, F. (1992). Poesía (1979-1987). Prólogo de L. García Montero. Madrid: Hiperión.

Benítez Reyes, F. (2013). Entrevista con Felipe Benítez Reyes. Ciclo Babelia. Recuperado de https://elpais.com/cult ura/2013/01/22/actualidad/13588774000_1358883783.html. 
Díez Fernández, J. I. (2009). Felipe Benítez Reyes y la poética de la melancolía. Dicenda. Cuadernos de Filología Hispánica, 27, 43-58.

García Montero, L. (1983). La otra sentimentalidad. El País, 8 de enero de 1983. Reedición en J. Egea, Á. Salvador y L. García Montero (1983). La otra sentimentalidad. (pp. 9-15). Granada: Don Quijote.

Iravedra, A. (ed.). (2007). Poesía de la experiencia. Madrid: Visor.

Jiménez Millán, A. (1995). Felipe Benítez Reyes: Poesia (1979-1987). Ínsula, 578, 26-27.

Jurado Morales, J. (ed.). (2014). Felipe Benitez Reyes, la literatura como caleidoscopio. Madrid: Visor.

Langbaum, R. (1996). La poesía de la experiencia: El monólogo dramático en la tradición literaria moderna. J. Jiménez Heffernan (ed.). A. Salvador (prólogo). Granada: Comares.

Maqueda Cuenca, E. (2006). El tema del tiempo en la poesía de Felipe Benítez Reyes. En G. Pulido Tirado (ed.). Tematologia: una introducción. (pp. 45-50). Jaén: Universidad de Jaén.

Medina, R. (1998). Poesía 'Fin de siglo': la experiencia y otros fantasmas poéticos. Revista de Estudios Hispánicos, 32, 597-612.

Molina Campos, E. (1988). La poesía de la experiencia y su tradición. Hora de poesía, 59-60, 41-47.

Moreno, M. P. (1997). Conversación con Luis García Montero. Poiesis. Revista de poesía, 4, 22-28.

Moreno, M. P. (2001). El lugar de la poesía de la experiencia en la literatura del siglo XX: ¿una posteridad calculada? Hispanic Poetry Review, 2(2), 72-89.

Mudrovic, M. (2000). La poesía de la experiencia rediviva: empatía y juicio, vida y arte, en Cuaderno de campo de Luis Javier Moreno. Hispanic Poetry Review, 2(1), 7-34.

Pérez García, N. (2007). El tiempo y sus fantasmas en la poesía de Felipe Benítez Reyes, Espéculo, 35.

Piquero, J. L. (1996). Artificio y misterio: la poesía de Felipe Benítez Reyes. Renacimiento, 11-12, 36-40.

Prieto de Paula, Á. L. (2003). Los artefactos confesionales. Babelia. El País, 18 de octubre.

Sánchez Torre, L. (1977). Un dibujo en el agua. Memoria y ficción en la poesía de Felipe Benítez Reyes. Zurgai, julio, 12-16.

Sanz, M. (2016). Éramos mujeres jóvenes. Una educación sentimental de la Transición española. Barcelona: Planeta.

Siles, J. (1991). Dinámica poética de la última década. Revista de Occidente, 122-123, 149-169.

Villena, L. A. De (1977). 10 menos 30. La ruptura interior en la "poesía de la experiencia". Valencia: Pre-Textos.

Villena, L. A. De (1992). Fin de siglo. Antología. Madrid: Visor.

\section{Notas}

1 En Poesía (1979-1987) de Benítez Reyes, constan los siguientes títulos de poemas con referencias metaliterarias: "Miseria de la poesía” (p. 76), “Anotaciones en un libro” (p. 77), "El joven artista (pp. 78-79), "La poesía” (p. 102), “Arte menor" (pp. 104-105), "Libros” (p. 125), "Catálogo de libros raros, agotados y curiosos” (p. 138). Paraíso manuscrito, Personajes secundarios y Pruebas de autor son los títulos tres de los seis libros compilados. Los textos con referencias a libros o a la escritura son: "Los vanos mundos" (p. 32), "Elegía” (p. 75), "Etopeya" (p. 86), a los que se suman los total o parcialmente metapoéticos, v. gr., "Oficio de intimidad" (p. 40), "El guerrero" (p. 44), "Bagatelas" (p. 85), "Sebastian Melmoth” (p. 99), “Exposición de motivos” (p. 112), “Encargo y envío” (pp. 129-130), “Arte menor” (pp. 104-105). En los versos se cita una gruesa nómina de escritores: Rubén Darío (p. 31), Juan de Tasis (p. 41), Julián del Casal (p. 62), Dante (p. 77), Carlos Marzal (p. 107), Juan del Encina (p. 110), Teócrito (p. 110), Francis Scott Fitzgerald (p. 123), Góngora (p. 129), Pío Baroja (p. 133), Meyrink (p. 133), Mujica (p. 133), Ovidio (p. 133), Kafka (p. 133), Fernando Pessoa-Álvaro de Campos (p. 133), Chesterton (p. 133), Melville (p. 133) y Stevenson (pp. 133 y 139).

2 Felipe Benítez Reyes, en Pruebas de autor (1980-1985) compone el texto metapoético titulado "Exposición de motivos" (Benítez Reyes, 1992, p. 112), alegato a favor de los "poetas oscuros" que tantean el misterio en las palabras "sin un sentido exacto, / hechas de niebla: / iguales a la vida”.

3 Molina Campos distingue el culturalismo externo de los novísimos y el interno de los poetas más recientes, para quienes las referencias culturales y los nombres propios se usan "solo como causa instrumental de un tema o de la concreción textual de ese tema” (Molina Campos, p. 44). Sin embargo, no siempre el culturalismo novísimo es externo, sino una 
forma de adentrarse en la historia y en el propio ser a partir de los elementos artísticos y literarios. El entramado de uso de la materia cultural de los poetas de la experiencia es complejo, con posturas a veces alejadas de los novísimos (deconstrucción irónica, por ejemplo) y otras más cercanas (rememoraciones, homenajes, motivos de inspiración...).

4 Prieto de Paula (2003) insiste en que ya está presente en Los vanos mundos la idea de que "conseguir un egotismo sin patetismo confesional exigió la construcción de un sujeto ficticio, no identificado automáticamente al yo del autor, según su idea [de Benítez Reyes] de que en el poema la emoción debe ser fingida”.

5 Abunda García Montero en la transitoriedad en la poesía de Benítez Reyes: “Todos los escenarios y las metáforas se convocan para hablarnos de una plenitud inmediatamente herida por el tiempo: el final del verano, los desechos de la fiesta en el jardín, el deslumbramiento corporal transitorio, las desconocidas que pudimos amar, las mujeres que solo perviven en su propia desaparición, el gozo resuelto en el hastío, el deseo cumplido como un beso en la niebla, como un espejismo en las vulgaridades de la realidad”. (García Montero en Benítez Reyes, 1992, p. 9)

6 El final del poema contiene un elogio de la juventud ligado al carpe diem: "Cuidad de todo amor y todo verso: / prestadle adoración y luego olvido. / Gastad esa moneda, la juventud. / Y que el tiempo, que huye, os sea generoso”. (Benítez Reyes, 1992, p. 35)

7 "Benedetto sia 'l giorno, e 'l mese e l'anno / e la stagione, e 'l tempo e l'ora e 'l punto / e 'l bel paese, e 'l loco ov'io fui giunto / da' duo begli occhi che legato m'hanno; // E Benedetto il primo dolce affanno / ch'i' ebbi ad esser con Amor congiunto, / e l'arco, e le saette ond'i' fui punto, / e le piaghe che 'nfin al cor mi vanno. // Benedette le voci tante ch'io // chiamando il nome de mia donna ho sparte, / e i sospiri, e le lagrime, e 'l desio; // e benedette sian tutte le carte / ov'io fama l'acquisto, e 'l pensier mio, / ch'è sol di lei, si cha'altra non v'ha parte".

8 Aunque se centra en Sombras particulares (1992), Díez Fernández (2009) alude a la mezcla en los libros anteriores del vitalismo, los ingredientes canallas y la melancolía, pasada tal amalgama por una ironía que pone distancia y rompe la seriedad de la identificación entre la voz lírica y lo escrito.

9 Jiménez Millán (1995) estudia la fusión entre la fiesta, la vida nocturna, las estrategias de seducción y su reverso en la fugacidad y el fracaso tal y como se exponen en Poesía (1979-1987).

10 Miguel Hernández en Perito en lunas desplegó la técnica de la adivinanza por sucesión de metáforas en la octava, aunque en su caso es canónica (octava real) y el lenguaje es culterano.

11 Pedro Salinas en "Underwood Girls" de Fábula y signo (1931) describe las teclas de la máquina de escribir y su actividad como si se tratara de chicas.

12 Abundan las referencias a escritores y artistas clásicos en la primera etapa de Benítez Reyes. "Anotaciones en un libro" (Benítez Reyes, 1992, p. 77) de Los vanos mundos acaba: "Un florentino engrandece su amor / creando el Paraíso y el Infierno". En "La esencia del tiempo" (Benítez Reyes, 1992, p. 110) de Pruebas de autor (1980-1985) concurren "las manos de cristal de Galatea”, Mozart, Juan del Encina, Teócrito y Endymión.

13 Intertextos bíblicos atraídos a lo profano se rastrean en el poema "Retratos de Monsieur Désir" de Los vanos mundos, que contiene una alusión a Petrarca, desmitificando la tradición clásica europea y la herencia religiosa. A la primera invocación al personificado Deseo sigue la afirmación del amor múltiple, para acabar tergiversando una frase de la liturgia católica "tuyo es el reino" (Benítez Reyes, 1992, p. 60). 